\title{
A RESPONSABILIDADE DOS SINDICATOS NA ELABORAÇÃO DE INSTRUMENTOS NEGOCIAIS COLETIVOS EM RELAÇÃO AO BANCO DE HORAS
}

\section{THE RESPONSIBILITY OF TRADE UNIONS IN TRANSACTION COLLECTIVE INSTRUMENTS ABOUT COMPENSATORY TIME}

\author{
Manuella de Oliveira Soares ${ }^{1}$ \\ Rui Carvalho Piva ${ }^{2}$
}

\section{RESUMO}

O Estado democrático de direto tem como objetivo dar garantia e eficácia aos direitos fundamentais a fim de que a dignidade humana seja preservada. Nessa trilha, dentre outros direitos fundamentais, encontra-se o direito a saúde que, em uma das suas vertentes, protege a saúde do trabalhador. Assim, o presente estudo, por meio de uma pesquisa bibliográfica, objetiva demonstrar que os sindicatos deveriam ser responsabilizados pelos danos causados aos trabalhadores quando elaboram instrumentos de negociação coletiva que permitem a criação do banco de horas com condições que colocam em risco a saúde dos trabalhadores.

Palavras-chaves: Saúde do trabalhador; banco de horas; sindicatos; responsabilidade civil; dano coletivo.

\begin{abstract}
The democratic State of Direct aims to provide assurance and effectiveness of fundamental rights in order that human dignity is preserved. In this way, among other fundamental rights is the right to health, in one of its aspects, protects workers' health. Thus, this study, through a bibliographical research aims to demonstrate that unions should be held responsible for damage caused to workers when preparing collective bargaining instruments to the creation of compensatory time with conditions that endanger the health of workers .

\footnotetext{
${ }^{1}$ Doutoranda em Sistema Constitucional de Garantia de Direitos pela Instituição Toledo de Ensino - ITE/Bauru, São Paulo, (Brasil). Mestre em processocivil e Cidadania pela UNIPAR, Professora da UEMS; Juíza leiga. E-mail: manuellauems@uol.com.br

${ }^{2}$ Advogado. Doutor em Direito pela Pontifícia Universidade Católica de São Paulo - PUC/SP, São Paulo, (Brasil). Com Pós-Doutorado na Universidade de Messina, Itália. Professor permanente do Centro Universitário de Bauru, mantido pela Instituição Toledo de Ensino
} 
Keywords: Occupational Health; Compensatory time; labour unions; civil responsability; collective damage.

\section{Introdução}

O Estado democrático de direto tem como objetivo dar garantia e eficácia aos direitos fundamentais a fim de que a dignidade humana seja preservada. Nessa trilha, pode-se dizer que o direito a saúde, a educação, ao trabalho, a moradia, ao lazer, a segurança, a previdência social, a proteção à maternidade e a infância são direito fundamentais sociais que devem ser garantidos pelo Estado.

Entre os mais importantes, está o direito a saúde, que está intimamente associado à dignidade humana. $\mathrm{O}$ direito fundamental a saúde pode ser analisado e defendido sob várias vertentes, sendo uma delas em relação a saúde do trabalhador.

Nessa seara é que o presente trabalho objetiva demonstrar que a satisfação dos direitos sociais, na implantação de um autêntico Estado social de Direito, é o caminho mais seguro para a concretude da teoria do mínimo existencial.

Portanto, primeiramente, o estudo aborda o direito a saúde como um direito fundamental de todas as pessoas, inclusive dos trabalhadores. Após, faz uma análise da proteção à saúde do trabalhador, sob o foco da jornada de trabalho.

Logo em seguida, analisa a flexibilização das normas de trabalho em relação ao instituto do banco de horas e sua influência na saúde do trabalhador.

Para finalizar, o presente estudo faz uma análise sobre a responsabilidade dos sindicatos ao permitirem a elaboração de instrumentos negociais coletivos que permitem a utilização do banco de horas de forma abusiva.

\section{A saúde como direito fundamental do ser humano}

Não há duvida de que o Estado democrático de direto tem como objetivo dar garantia e eficácia aos direitos fundamentais a fim de que a dignidade humana seja preservada. Nessa 
trilha, antes de qualquer colocação, importante tecer pequenas considerações a respeito dos direitos humanos e sua importância na efetivação da dignidade da pessoa humana.

Seguindo os ensinamentos de Ingo Wolfgan Sarlet (2002) a dignidade humana deve ser encarada como a qualidade intrínseca e distintiva de cada ser humano que o faz merecedor do respeito do Estado. Isso, por consequência, implica na garantia de um complexo de direitos e deveres fundamentais que protege a pessoa de todo e qualquer ato de cunho degradante e desumano, além de propiciar e promover a sua participação livre e corresponsável nos destinos da própria existência e da vida em comunhão como os demais seres humanos.

Nesse cenário, pode-se afirmar que garantir os direitos fundamentais é garantir a dignidade da pessoa humana. Vários são os direitos tutelados tidos como fundamentais no nosso ordenamento jurídico.

A Constituição Federal de 1988, sob a rubrica do Titulo II, adotou uma espécie de clausula de abertura material para definir quais seriam os direito fundamentais protegidos no Brasil, mais precisamente no artigo $5, \S 2^{\circ}$, onde aduz que os direitos e garantias expressos no referido artigo não excluíam outros decorrentes do regime dos princípios por ela adotados ou dos tratados internacionais que o Brasil faz parte.

Ao ler a carta maior, percebe-se que o constituinte elegeu a categoria de direito fundamental todo e qualquer direito que está consubstanciado os valores da liberdade, da democracia politica e da democracia econômica e social. Ademais, todo direito que tem como característica a historicidade, a universalidade, a autogeneratividade, a irrenunciabilidade, a limitabilidade e a possibilidade de concorrência. (NUNES JUNIOR; DALLARI, 2010).

Os direitos fundamentais foram sendo alcançados aos poucos, conforme a evolução da sociedade, com o único objetivo de se efetivar a dignidade da pessoa humana.

O ponto inicial dos direitos humanos foi o cristianismo, com Santo Tomás de Aquino, diretamente ligado à concepção dos jusnaturalismo, com a ideia central de que o homem possuía direitos básicos e naturais que deveriam ser respeitados, inclusive com a limitação ao poder absolutista e monárquico. Mas a positivação dos direitos e garantias fundamentais deu-se efetivamente somente em 1776, por intermédio do denominado Bill of Rigths de Virginia. 
Nesse momento histórico, a preocupação era limitar o poder estatal, fazendo com a que a Constituição tivesse duas finalidades básicas: demarcar a separação orgânica dos poderes e assegurar liberdades, por meio da constitucionalização formal dos direitos e garantias individuais, denominados de direitos fundamentais de primeira geração.

Nessa era de positivação dos direitos, pode-se afirmar que imperava o formalismo jurídico. Os princípios liberais, contudo, não foram suficientes para conter as crises sociais e garantir as exigências coletivas, o que levou ao seu declínio. Surge, assim, a partir do século XIX várias doutrinas sociais, defendendo a intervenção do Estado na ordem econômica para a realização dos direitos sociais.

Nesse cenário, surgiram os direitos fundamentais de segunda geração. São direitos que revelam a busca da realização da igualdade, de uma efetiva democracia social, tais como direito a saúde e educação, além da liberdade de sindicalização e direito a greve.

Depois da segunda guerra mundial, a perspectiva de reconstrução dos direitos do homem veio adornado de um elemento novo, a saber, a noção de solidariedade dos povos. Com efeito, os chamados direitos fundamentais de terceira geração não tem por objetivo propriamente a preservação das liberdades individuais ou do ser humano como ser social, mas sim do ser humano como parte da humanidade. Logo, não atina a um grupo especifico ou a um estado determinado, mas a humanidade, como valor ético maior a permear a relação entre os povos e os Estados.

A necessidade de garantia dos direitos fundamentais, com o intuito de assegurar justiça social e a dignidade da vida humana em patamares mínimos, atinge tal grau de importância, especialmente após a segunda guerra mundial, que passaram a ganhar proteção internacional.

De tal modo, paralelamente à internalização dos direitos fundamentais, convém ressaltar que alguns autores defenderam a existência dos direitos de quarta geração, em decorrência da própria globalização, os quais consistem no direito a democracia, direito a informação e o direito ao pluralismo.

Nesse cenário, pode-se dizer que o direito a saúde, a educação, ao trabalho, a moradia, ao lazer, a segurança, a previdência social, a proteção à maternidade e a infância são direito fundamentais sociais (SERRANO, 2012).

Direitos sociais para Vidal Serrano Nunes Junior seriam 
(...) o subsistema dos direitos fundamentais que, reconhecendo a existência de um segmento social economicamente vulnerável, busca, quer por meio de atribuição de direitos prestacionais, quer pela normatização e regulação das relações econômica, ou ainda pela criação de instrumentos assecuratórios de tais direitos, atribuir a todos os benefícios da vida em sociedade (2009, p. 70).

Nessa trilha, os direitos fundamentais sociais são aqueles que a Constituição Federal os relaciona como a vida humana, possibilitando a igualdade no exercício da dignidade, por meio de elementos vitais, como a educação e saúde (SERRANO, 2012). Portanto, a saúde é um direito fundamental social protegido pela nossa Constituição Federal.

A saúde é um bem jurídico que depende de varias características individuais, físicas e psicológicas, além de depender do ambiente social e econômico (NUNES JUNIOR; DALLARI, 2010).

Desse modo, a concepção do direito a saúde como condição de vida e bem estar social constitui o chamado direito social, que ultrapassa a visão da oferta dos serviços de saúde, indo muito mais além, estando intimamente associado à dignidade humana, decorrente de uma estrutura do Estado Democrático de Direito.

Portanto, o direito a saúde assume especial relevância, porquanto de pouca valia os demais direitos, tais como o de liberdade entre outros, se a pessoa não tem uma vida saudável que lhe permita fazer suas escolhas.

\section{3. $O$ direito à saúde do trabalhador}

O direito fundamental a saúde pode ser analisado e defendido sob várias vertentes. Uma delas é em relação a saúde do trabalhador. A saúde do trabalhador também é um direito humano, vez que trata-se de um direito inerente a pessoa, sem o qual a dignidade da pessoa humana estaria seriamente ameaçada.

A Constituição Federal, em especial nos artigos $1^{\circ}, 5^{\circ}, 6^{\circ}, 7^{\circ}, 200$ e 225, trata a saúde do trabalhador como uma norma de ordem pública, devendo essas normas serem aplicadas de imediato diante de quaisquer circunstâncias, em respeito sempre ao paradigma maior do sistema jurídico brasileiro: a dignidade da pessoa humana. 
Nestes dispositivos se encontra, então, a nítida interdependência entre o direito a vida, a saúde do trabalhador e ao meio ambiente do trabalho equilibrado, interpretação levada a efeito com base no princípio ontológico da dignidade da pessoa humana.

A satisfação dos direitos sociais, na implantação de um autêntico Estado social de Direito, é o caminho mais seguro para a concretude da teoria do mínimo existencial. Sem a realização dos direitos sociais que configuram o chamado patamar civilizatório mínimo, na feliz expressão de Mauricio Godinho Delgado ( 2011), não há falar em direitos humanos sociais ou de segunda geração, os quais desempenham dupla função, de limitar a autonomia do mercado e, em consequência disso, de materializar a justiça distributiva, especialmente através de um sistema de prestações e serviços públicos, para a satisfação das necessidades básicas da população.

De tal modo que a saúde do trabalhador, como espécie do gênero, compõe, ineludivelmente, o chamado conteúdo essencial da dignidade da pessoa humana, não podendo, jamais, ser postergada sua proteção .

O termo saúde do trabalhador surgiu no Brasil sob o bojo do Movimento pela Reforma Sanitária, que se intensificou no país a partir da década de 1980, tendo, na Reforma Sanitária Italiana, seu exemplo inspirador (TEIXEIRA, 1994). A união dos esforços de técnicos de saúde ligados às universidades e ao Ministério da Saúde com os trabalhadores, dentro da emergência do Novo Sindicalismo, estabeleceu as bases desse conjunto de saberes e práticas denominadas Saúde do Trabalhador.

A preocupação com a saúde do trabalhador nasce como contraponto aos modelos hegemônicos das práticas de intervenção e regulação das relações saúde-trabalho da Medicina do Trabalho, Engenharia de Segurança e Saúde Ocupacional.

É possível afirmar que momento culminante de mobilização popular pela saúde do trabalhador no Brasil ocorreu na VIII Conferencia Nacional de Saúde, e na I Conferência Nacional de Saúde do Trabalhador, ambas em 1986 e em Brasilia - DF. Consolidou-se, dessa forma, como conceito dentro dos textos legais da Constituição de 1988 e na Lei Orgânica da Saúde (Lei 8.080), que em seu artigo $6, \S 3^{\circ}$ define saúde do trabalhador como sendo um conjunto de atividades que se destina, através das ações de vigilância epidemiológica e vigilância sanitária, à promoção e proteção da saúde dos trabalhadores, assim como visa à recuperação e reabilitação da saúde dos trabalhadores submetidos aos riscos e agravos advindos das condições de trabalho. 
A saúde do trabalhador deve ser pensada como um direito individual subjetivo que alcança várias necessidades, dentre elas a que diz respeito ao direito da saúde em sentido estrito e ao meio ambiente de trabalho adequado. A saúde do trabalhador é espécie da saúde geral, e como tal deve ser amparada pelo Sistema Único de Saúde, conforme a Lei Orgânica de Saúde (Lei n $\left.{ }^{\circ} 8.080 / 90\right)$, artigo $6^{\circ}, \mathrm{I}, c$ e parágrafo $3^{\circ}$.

Neste sentido, destaca-se o papel da Organização Internacional do Trabalho que adotou recomendações para a proteção da saúde do trabalhador (SILVA, 2007, p.12).

Pode-se dizer que o conteúdo essencial do direito à saúde do trabalhador tem dois aspectos essenciais, quais sejam: $1^{\circ}$ ) direito à abstenção: a) do Estado a não-interferência no exercício do direito; b) do empregador - quanto ao fator tempo de trabalho, a abstenção de exigir trabalho em horas extras habituais, nos intervalos intra e interjornadas, nos dias de repouso semanal e feriados, nos períodos de férias, assim como de exigir trabalho da mulher durante a licençamaternidade e dos menores de 18 anos trabalho noturno, perigoso ou insalubre; quanto ao fator saúde mental, a abstenção de tratamento rigoroso quando das ordens e fiscalização do serviço, bem como de exigir produtividade superior às forças físicas e mentais do trabalhador; $2^{\circ}$ ) direito de prevenção: a) do Estado - as prestações atribuídas ao SUS (na forma do $\S$ $3^{\circ}$ do art. $6^{\circ}$ da Lei $n^{\circ}$ 8.080/90), a obrigação de editar normas de saúde, higiene e segurança para a redução dos riscos inerentes ao trabalho, bem como de proteger o meio ambiente geral e fiscalizar o cumprimento das normas de ordem pública por parte do empregador; b) do empregador - a obrigação de cumprir tais normas, especialmente as NRs, para a proteção do meio ambiente do trabalho e da saúde do trabalhador, assim como de contratar seguro contra acidentes do trabalho. (SILVA, 2007, p. 136).

Nessa trilha pode-se afirmar que a proteção a Saúde do Trabalhador é realizada por intermédio da atuação da vigilância dos perigos e riscos inerentes ao trabalho, a assistência à saúde e a abordagem e a conduta apropriadas aos determinantes sociais, individuais ou de grupos, que podem impactar de modo negativo na saúde dos trabalhadores (HIAVEGATTO, 2010).

Portanto, a saúde do trabalhador se trata de um direito fundamental, de um direito imprescindível ao obreiro. Não há duvida que sua proteção deve ser integral. Não é admissível que nos dias atuais, de tanta tecnologia e avanços na área de saúde, ainda exista inúmeros fatores na relação de emprego que interfira diretamente na saúde do trabalhador, prejudicando-o, causando adoecimentos ocupacionais e acidentes de trabalhos. 
Garantir a saúde ao trabalhador é garantir o próprio desenvolvimento das atividades laborais. A saúde do trabalhador tem que estar acima de qualquer outro direito do empregador no exercício de seus poderes empresariais. Nenhuma liberdade de empresa pode prevalecer diante da saúde do trabalhador, até porque o empresário deve ser devedor de segurança. (SILVA, 2012).

\section{A Flexibilização da Jornada de Trabalho e sua relação com a saúde do trabalhador}

A saúde do trabalhador está relacionada com inúmeros fatores. Um deles é a jornada de trabalho, que é a quantidade de labor diária que o empregado está a disposição do empregador.

O período considerado no conceito de jornada corresponde ao lapso temporal diário, em face de o verbete, em sua origem, referir-se à noção de dia (por exemplo, no italiano: giorno- giornata; e no francês: jour- journée).

Como se sabe, com a Revolução Francesa, ainda que se tenha produzido uma historia de êxito incontestável e progresso fantástico, houve um aumento intensivo e extensivo da jornada de trabalho.

Alias, Karl Marx, em sua obra clássica "O capital”, narra inúmeros trechos que relatam os efeitos negativos das extensas jornadas de trabalho inglesas, de até 18 horas, inclusive para mulheres e crianças (MARX, 2004). Nesse cenário, foi que de 1833 a 1847 houve inúmeras greves na Grã Bretanha, que resultaram na aprovação pelo parlamento da primeira lei geral limitadora da jornada de trabalho, "lei das 10 horas", que fixava a jornada diária de trabalho em 10 horas para as industrias têxteis da Grã Bretanha. (SILVA, 2013).

Depois disso as lutas se intensificaram e a jornada foi reduzida para oito horas, quando em $1^{\circ}$ de maio de 1886 se realizou uma manifestação de trabalhadores em Chicago (EUA) coma finalidade de reduzir a jornada de trabalho (SILVA, 2013).

A luta continuou em muitos países até que em 1919, a OIT aprovou a convenção $n^{\circ} 1$ onde fixou a jornada máxima de trabalho em 8 horas diárias e 48 horas semanais, fazendo restrições ao trabalho extraordinário. 
Avanços dos estudos e modernas pesquisas sobre saúde têm mostrado a importância da jornada reduzida de trabalho para a saúde do trabalhador. A duração da jornada de trabalho já não é mais uma norma estritamente econômica, já que pode alcançar a função determinante de norma de saúde e segurança laboral, assumindo, portanto, o caráter de norma de saúde pública.

Os fundamentos para a limitação da jornada de trabalho são pelo menos quatro: biológicos, que dizem respeito aos efeitos psicofisiológicos causados ao empregado, decorrentes da fadiga; sociais, o empregado deve conviver e relacionar-se com outras pessoas, de dedicar-se à família, de dispor de horas de lazer; econômicos que dizem respeito à produção a empresa, em que o empresário aumenta a jornada de trabalho, pagando horas extras, justamente para aumentar a produção; humanos(...).

O principal fundamento humano é diminuir os acidentes do trabalho. É sabido que, no período em que o trabalhador presta serviços cansado ou quando faz horas extras, ocorre maior índices de acidentes do trabalho, principalmente em virtude da fadiga. Muitas vezes, o empregado, para receber o salário das horas extras, presta maior numero de horas do que tem condições, e é justamente nesse momento que podem ocorrer os acidentes do trabalho". (MARTINS, 2013, p. 489-490)

A Constituição Federal apreendeu de modo exemplar essa nova leitura sobre jornada de trabalho- a de que a mesma tem caráter de norma de saúde publica- e sabiamente arrolou como direitos dos trabalhadores a redução dos riscos inerentes ao trabalho, por meio de normas de saúde, higiene e segurança (artigo 7, XXII) e a determinou a limitação da jornada de trabalho, em regra, para 8 horas diárias (artigo 7, XIII e XIV).

O maior ou menor numero de horas da jornada de trabalho, bem como o maior ou menor espaçamento entre as jornadas atuam diretamente na deterioração ou melhoria das condições internas de trabalho na empresa, comprometendo ou aperfeiçoando uma estratégia de redução dos riscos e malefícios inerentes ao ambiente de prestação de serviço.

A modulação da duração do trabalho é parte integrante de qualquer politica de saúde publica, uma vez que influencia, exponencialmente, a eficácia das medidas de medicina e segurança do trabalho adotadas na empresa (DELGADO, 2011, p. 807).

O estudo dos efeitos da jornada de trabalho excessiva no desfrute dos direitos fundamentais dos trabalhadores, sobretudo do direito a saúde, necessita ter em conta os dois aspectos da ordenação do tempo de trabalho: o aspecto quantitativo (que diz respeito a 
quantidade de tempo de trabalho), e o qualitativo(que se refere a distribuição da jornada ao longo do tempo).

Atualmente a vertente qualitativa vem ganhando cada vez mais importância, até porque vem se exigindo uma produção cada vez maior, o que interfere diretamente na jornada de trabalho, que fica mais intensa e cansativa, e, por consequência, na saúde do trabalhador.

Portanto, não há dúvida de que os períodos de descanso e as pausas intrajornadas são, ainda, a retaguarda da dessa da dignidade do trabalhador e garantia de sua saúde.

Faz-se necessário implantar uma cultura de solidariedade, de modo que a liberdade empresarial e a busca do livre exercício ao capitalismo encontrem freio na necessidade de se garantir saúde ao trabalhador. Exigir jornada de trabalho extenuante é desrespeitar a dignidade do trabalhador.

\section{O Banco de Horas e a ofensa à saúde do Trabalhador}

Embora a Constituição Federal de maneira intensa preveja inúmeras disposições de proteção ao trabalhador, inclusive sobre jornada de trabalho, há um movimento mundial que vem flexibilizando essas normas trabalhistas afim de que as mesmas sejam compatibilizadas com as mudanças de ordem econômica, tecnológica ou social existentes na relação entre o capital e o trabalho.

Na ótica de Sergio Pinto Martins a flexibilização das normas trabalhistas proporciona um conjunto de regras ao trabalhador que respeitem os seus direitos mínimos somados à garantia de manutenção da empresa com a possibilidade de adaptação de seu negócio em épocas de crise econômica. Nesse sentido, o citado autor afirma:

Para fiscalizar essa flexibilização, com essa maleabilidade, é que o sindicato passa a deter o papel principal, ou seja, na participação das negociações coletivas que conduzirão ao acordo ou à convenção coletiva de trabalho, de modo a permitir também a continuidade do emprego do trabalhador e a sobrevivência da empresa, assegurando um grau de lucro razoável à última e certas garantias mínimas ao trabalhador. É uma forma de adaptação das normas vigentes às necessidades e conveniências de trabalhadores e empresas.(MARTINS, 2013, p. 527) 
Em vários setores do direito do trabalho pode-se falar em flexibilização. Um deles é em relação a jornada, que pode dar-se de quatro formas: realização de horas extras, anualidade das horas trabalhadas (banco de horas), jornada de trabalho flexível e semana reduzida de trabalho, na qual o trabalhador concentra as horas trabalhadas em um período menor da semana, utilizando o restante dos dias para descansar (Chahad, 2002).

Dentro dessa seara, o presente estudo destaca o banco de horas, que se caracteriza como sendo um mecanismo compensatório de jornada de trabalho no direito Brasileiro.

O Banco de Horas foi criado pela Lei $n^{\circ}$ 9601/98 e trata-se de um sistema de compensação de horas extras mais flexível, embora exija uma autorização por convenção ou acordo coletivo, possibilitando à empresa adequar a jornada de trabalho dos empregados às suas necessidades de produção e demanda de serviços.

O empregado faz a hora extra e depois tem um determinado período para compensála, não indo trabalhar no período em que, outrora, trabalhou além do limite da jornada de trabalho.

O problema é que o empregado não recebe nenhuma quantia a mais em dinheiro pelas horas extraordinárias trabalhadas e ainda não as compensa em tempo razoável, já que a Lei permite um tempo excessivamente longo para a realização dessa compensação, qual seja, de um ano.

O que se questiona é se essa compensação anual do banco de horas não vai contra os ditames constitucionais de proteção a saúde do trabalhador. O fato da Lei permitir que o empregador exija trabalho extraordinário dos empregados por vários meses do ano, com a faculdade de compensar a sobrejornada com a redução de trabalho em outros dias (quase sempre da maneira que melhor lhe convier), afronta uma norma de ordem publica.

Ao que se vê, o trabalhador tem duplo prejuízo com o banco de horas já que, além de trabalhar por horas contínuas fazendo jornada extraordinária, ainda não recebe o respectivo adicional. Prejuízo econômico e para a saúde.

Nesses termos, é irresistível considerar a Lei do Banco de Horas como sendo inconstitucional, por ser um incentivo à utilização do trabalho em jornada extraordinária, contrariando o ideal maior previsto na Constituição Federal, que é de favorecer a saúde e segurança do trabalhador. 
Infelizmente, o limite anual de compensação das horas estabelecido pelo Banco de Horas favorece somente as empresas. O empregado, às vezes, é obrigado a trabalhar grandes períodos de tempo com jornada excedida, privando-se do convívio familiar e da sua saúde, para manter-se no emprego.

Tal instituto fere vários preceitos estabelecidos na Constituição Federal, tanto em relação aos direitos dos trabalhadores, quanto, até mesmo, princípios econômicos, pois o Banco de Horas acaba evitando a contratação de novos trabalhadores, ao sobrecarregar os já existentes em épocas de aumento de demanda.

Mas delimitando os prejuízos em relação apenas à saúde do trabalhador, que é o tema do presente estudo, tem-se que além do limite de compensação das horas ser extremamente longo, também o é injusto.

Além disso, se for considerado que a Constituição Federal prevê o pagamento das horas extraordinárias com um adicional de no mínimo 50\%, justamente como uma forma de compensação dos prejuízos ao trabalhador (fadiga, horas roubadas do convívio familiar e social, etc), o mesmo raciocínio deveria ser mantido para o Banco de horas.

Nessa trilha, toda hora trabalhada de forma extraordinária nos moldes da Lei $n^{\circ}$ 9601/98, deveria haver uma compensação a base de uma hora e meia regular de trabalho nos dias normais e duas horas para cada hora extraordinária realizada nos domingos e feriados.

Se o legislador já fez a previsão anteriormente de pagamento com adicional de no mínimo 50\% no caso de trabalho extraordinário ou de pagamento em dobro, no caso de trabalho em feriados, justamente por ter ciência dos malefícios que o trabalho extraordinário causa ao obreiro, em especial à sua saúde, por que não fazer o mesmo raciocínio para o banco de horas?

Seria o mínimo aceitável, já que o trabalhador pode levar até um ano para poder ter o benefício do descanso pelas horas extraordinárias trabalhadas a mais. Se a Carta Magna determina que o empregado receba mais em dinheiro para trabalhar além da jornada, então que seja feito uma analogia e que ele descanse mais por trabalhar mais pelo sistema do banco de horas.

O problema é sério e vem crescendo cada dia mais, uma vez que os Sindicatos a cada dia vêm realizando mais esse tipo de acordo de flexibilização de jornada.

A intensificação do trabalho do trabalho_ que envolve também o aspecto qualitativo da jornada de trabalho, pois implica uma maior extração de mais-valia 
relativa, inclusive pela inadequada distribuição do tempo de trabalho _, levada a um nível insuportável na indústria e nalguns subsetores dos serviços, especialmente nos transportes e instituições financeiras, tem conduzido a um numero preocupante de doenças ocupacionais, o que deve ser objeto de atenção especial por parte do governo brasileiro (SILVA, 2013, p. 142).

Ante essa situação de extremo perigo à tão anunciada harmonia social, urge que o governo, bem como os órgãos que regulam as relações laborais, entre outros envolvidos, comecem uma cruzada pela restauração dos limites efetivos de jornada de trabalho, a fim de que os obreiros sejam tratados com a dignidade que merecem, respeitando seus direitos fundamentais.

Ao se confrontar os dados das jornadas mais extensas por setor da atividade econômica com os dados disponíveis a respeito de acidentes de trabalhos nesses setores, temse uma indicação de que a duração do tempo de trabalho pode contribuir para o surgimento dos acidentes laborais e, sobretudo, das doenças do trabalho (SILVA, 2013).

O tempo de trabalho, muito além do normal ou recomendado conduz a uma grande quantidade de doenças ocupacionais. Nesse cenário, é que há uma grande preocupação com o instituto do Banco de Horas, já que o mesmo exige uma jornada de trabalho longa ao obreiro, que só recebe a compensação pela mesma tempos depois e ainda, se não bastasse, de forma indevida, se for feita uma interpretação sistemática das leis justrabalhistas.

Um processo prolongado de fadiga induz à instalação da fadiga crônica, que não cede nem mesmo com o repouso diário. Esse quadro de fadiga patológica compromete o sistema imunológico, deixando o trabalhador muito mais vulnerável às doenças, além de produzir insatisfação com o serviço, absenteísmo, baixa produtividade e maior número de acidentes de trabalho (OLIVEIRA, 1998, p. 142).

A compensação teria que ser feita em período bem menor que um ano, na proporção de uma hora e meia para cada hora extraordinária trabalhada, ou duas horas nos dias de feriado, e na data em que for de interesse do empregado. Talvez, só dessa maneira, o prejuízo seria diminuído e o direito fundamental à saúde respeitado. Caso contrário, estará ocorrendo uma grande afronta a dignidade humana do trabalhador submetido ao Banco de Horas.

\section{A responsabilidade dos sindicatos ao permitirem o Banco de Horas}


Como dito, a flexibilização da jornada de trabalho, como fator prejudicial à saúde do trabalhador, não poderia ser aceita. Todavia, o que se percebe é que se trata de uma pratica diuturna, com o beneplácito dos sindicatos, dos auditores fiscais do trabalho e, porque não, da própria justiça do Trabalho.

Os sindicatos, em especial, não poderiam permitir tamanha flexibilização na jornada de trabalho. A autonomia coletiva para realização de tais acordos encontra limites de ordem material, não podendo o principio da adequação setorial negociada se sobrepor a Constituição Federal.

A flexibilização somente pode ser aceita quando eleve o patamar dos direitos do trabalhador a nível superior que o estabelecido em lei, nunca o contrário.

Também não prevalece a adequação setorial negociada se concernente a direitos revestidos de indisponibilidade absoluta (e não indisponibilidade relativa), os quais não podem ser transacionados nem mesmo por negociação sindical coletiva. Tais parcelas são aquelas imantadas por uma tutela de interesse público, por se constituírem em um patamar civilizatório mínimo que a sociedade democrática não concebe ver reduzido em qualquer segmento econômico - profissional, sob pena de se afrontar a própria dignidade da pessoa humana e a valorização mínima deferível ao trabalho (arts. $1^{\circ}$, III e 170, Caput, CF/88). Expressam, ilustrativamente, essas parcelas de indisponibilidade absoluta a anotação de CTPS, o pagamento de salário mínimo, as normas de medicina e segurança do trabalho. (DELGADO, 2011, p. 824- grifei)

Portanto, os Sindicatos, que devem ser entidades representativas que defendem direitos trabalhistas visando melhores condições de labor e vida, não estão cumprindo o seu papel ao permitirem tamanha ruína à saúde do trabalhador. Não há dúvidas de que tal conduta permissiva causa dano ao empregado.

Nessa seara, se causa dano, há que se falar em responsabilidade, uma vez que há uma conduta culposa, dano e nexo causal entre eles. A conduta danosa está configurada quando o sindicato consente e dá seu aval à elaboração de um instrumento coletivo que vai de encontro com a Constituição Federal, instrumento normativo máximo que consagra o direito à saúde do trabalhador como direito fundamental. Se, eventualmente, a conduta dolosa do sindicato não conseguir ser comprovada, no mínimo restará caracterizada a conduta culposa na modalidade de negligência, já que uma vez permitindo a elaboração de tais instrumentos negociais coletivos, se omitindo em relação ao seu papel fundamental, que é proteger o empregado. 
O dano, indubitavelmente, resta comprovado quando o trabalhador é submetido a jornada extraordinária sem receber o respectivo adicional, sendo compensadas as horas tempos depois e ainda de maneira simples (e não uma hora de trabalho por uma hora e meia de descanso). Não há dúvida de que estamos frente a um dano à saúde do trabalhador e a sua segurança.

Quanto ao nexo, também resta cabalmente configurado, pois o dano à saúde do trabalhador não ocorreria se não houvesse a negociação coletiva elaborada pelo sindicato permitindo o banco de horas na empresa.

Portanto, uma vez configurados os três requisitos, há que se falar em responsabilidade, tudo com fulcro nos artigos 186 e 927, ambos do Código Civil, que prelecionam, respectivamente, que "todo aquele que, por ação ou omissão voluntária, negligência ou imprudência, violar direito e causar dano a outrem, ainda que exclusivamente moral, comete ato ilícito" e, "todo aquele que, por ato ilícito, causar dano a outrem, fica obrigado a repará-lo".

Não se quer proibir a realização de negociação coletiva que permita o banco de horas, ou defender a inconstitucionalidade do instituto. $\mathrm{O}$ que deve ser destacado é que o mesmo precisa ser elaborado com cláusulas que não prejudiquem sobremaneira a saúde do trabalhador, como vem ocorrendo diuturnamente em nosso país.

Se, por exemplo, a compensação de horas fosse realizada, como dito, na proporção de uma hora e meia para cada hora extraordinária trabalhada, ou duas horas nos dias de feriado; na data em que for de interesse do empregado e no prazo razoável de até um ou dois meses, não haveria tantos problemas, uma vez que os danos à saúde estariam minimizados.

Todavia, ocorre que essas regras não são aplicadas, o que acaba por ser demasiadamente prejudicial ao empregado. Da forma que vêm ocorrendo, não há dúvidas da nocividade que o banco de horas vem causando, o que poderia ser evitado com uma postura mais proativa dos sindicatos. Agindo de maneira permissa, os sindicatos atualmente vêm causando dano moral dano moral coletivo a todos os empregados que estão sob a égide dos instrumentos negociais coletivos que permitem o banco de horas em condições absurdas.

O dano moral coletivo não segue as mesmas regras que regem as relações individuais, já que o mesmo restará configurado independentemente do número de pessoas afetadas; ocorrendo quando o ilícito acabar por afetar direitos pertencentes a uma determinada 
coletividade. O dano moral coletivo relaciona-se com o bem da vida que se pretende proteger, e não com o sujeito eventualmente afetado. No caso das negociações coletivas que permitem o banco de horas de forma abusiva, haverá dano à coletividade de trabalhadores submetidos aquele instrumento coletivo que sofreram lesão à saúde.

Sobre o assunto, ensina Medeiros Neto:

Resta evidente, com efeito, que, toda vez em que se vislumbrar o ferimento a interesse não-patrimonial, do qual titular uma determinada coletividade (em maior ou menor extensão) configurar-se-á dano passível de reparação, sob a forma adequada a esta realidade jurídica peculiar aos direitos transindividuais, que se traduz em uma condenação pecuniária arbitrada judicialmente, reversível a um fundo específico, com o objetivo de reconstituição dos bens lesados (MEDEIRO NETO, 2007, p. 129)

Assim, a condenação dos sindicatos no ressarcimento do dano causado aos empregados objetiva oferecer à coletividade de trabalhadores uma compensação pelo dano sofrido, atenuando, em parte, as consequências da lesão; ao mesmo tempo em que visa a aplicar uma sanção de índole inibitória pelo ato ilícito praticado pela entidade para que não celebre outros instrumentos negociais nos mesmos moldes.

Não se pode permitir que os sindicatos continuem agindo de modo contrário aos interesses dos trabalhadores, uma vez que são entidades criadas para justamente protegê-los de acordo com a Carta Magna (artigo 8, III).

Infelizmente há tempos os sindicatos vêm fazendo vistas grossas para tamanho desrespeito ao trabalhador, ignorando todo o clamor da doutrina majoritária trabalhista que sempre criticou veemente o instituto do Banco de Horas nos moldes previsto em lei. Não é mais possível aceitar tamanho desplante a direito fundamental dos empregados.

A responsabilização dos sindicatos talvez seja a maneira mais rápida e eficaz de barrar esse atentado à saúde do trabalhador, que vem se tornando uma prática cada vez mais comum na sociedade. O poder judiciário, ao condenar tal prática, estará efetivando a proteção dos diretos fundamentais, que não deve ser preservada apenas do plano normativo. Cabe ao poder judiciário ser comprometido com a tutela dos direitos fundamentais, consciente da dimensão político-social da jurisdição, a qual tem outros escopos além do estritamente jurídico.

\section{Considerações Finais}


Ante a todo o exposto, primeiro pode-se falar que a dignidade humana deve ser encarada como a qualidade intrínseca e distintiva de cada ser humano que o faz merecedor do respeito do Estado, o que implica, por consequência, na garantia de um complexo de direitos e deveres fundamentais que protege a pessoa de todo e qualquer ato de cunho degradante e desumano.

Nesse cenário, a Constituição Federal adotou uma espécie de cláusula de abertura material para definir quais seriam os direito fundamentais protegidos no Brasil, mais precisamente no artigo $5, \S 2^{\circ}$, onde aduz que os direitos e garantias expressos no referido artigo não excluíam outros decorrentes do regime dos princípios por ela adotados ou dos tratados internacionais que o Brasil faz parte.

Dentro do rol dos direitos fundamentais protegidos pela nossa carta Magna, encontra-se o direito à saúde, que deve ser encarado como sendo a concepção do direito a uma boa condição de vida e bem estar social, que ultrapassa a visão da oferta dos serviços de saúde, indo muito mais além, estando intimamente associado à dignidade humana, decorrente de uma estrutura do Estado Democrático de Direito. Portanto, o direito a saúde assume especial relevância, porquanto de pouca valia os demais direitos, tais como o de liberdade entre outros, se a pessoa não tem uma vida saudável que lhe permita fazer suas escolhas.

Nessa trilha, foi demonstrado que o direito a saúde engloba a saúde do trabalhador, que surgiu no Brasil sob o bojo do Movimento pela Reforma Sanitária.

A saúde do trabalhador deve ser pensada como um direito individual subjetivo que alcança várias necessidades, dentre elas a que diz respeito ao direito a saúde em sentido estrito e ao meio ambiente de trabalho adequado.

Não há dúvida que sua proteção deve ser integral. Não é admissível que nos dias atuais, de tanta tecnologia e avanços na área de saúde, ainda exista inúmeros fatores na relação de emprego que interfira diretamente na saúde do trabalhador, prejudicando-o, causando adoecimentos ocupacionais e acidente de trabalhos. Portanto, toda norma que não estiver em consonância com essa ideia, deve ser rechaçada pelos aplicadores do Direito.

Nesse contexto, é que o presente estudo demonstra que o instituto do Banco de Horas, do modo que está idealizado atualmente, não vem cumprindo a sua finalidade. 
A compensação anual do banco de horas vai contra os ditames constitucionais de proteção a saúde do trabalhador. O fato da Lei permitir que o empregador exija trabalho extraordinário dos empregados por vários meses do ano e só descanse tempos depois, afronta uma norma de ordem publica, diminuindo a dignidade do trabalhador.

Infelizmente, a realização de instrumentos de negociação coletiva que fazem a previsão de banco de horas está sendo uma pratica diuturna com o beneplácito dos sindicatos. Como forma de barrar tal pratica, entende-se que os sindicatos devem ser responsabilizados por realizarem inúmeros instrumentos de negociação coletiva que permitem a utilização de banco de horas pela empresa de forma irresponsável e abusiva.

É extreme de dúvidas de que essa postura dos sindicatos vem causando dano moral coletivo a todos os trabalhadores que estão sob a égide desses acordos, uma vez que direitos fundamentais vêm sendo desrespeitados e danos irreversíveis vêm se verificando.

Se assim não for entendido, estar-se-á trocando a dignidade do trabalhador pelo lucro desarrazoado. Não se quer proibir a autonomia da vontade e a aplicação do principio da adequação setorial negociada, mas apenas coibir e penalizar tudo que contrarie a incidência dos direitos fundamentais nas relações privadas de trabalho, já que as mesmas devem se sobrepor aos interesses ilegítimos do poder empregatício.

\section{REFERÊNCIAS BIBLIOGRÁFICAS}

CHAHAD, J. P. Z. Emprego flexível e mercado de trabalho no Brasil. In: Fundação Instituto de Pesquisas Econômicas. Trabalho flexível e modalidades especiais de contrato de trabalho: evidências empíricas no caso brasileiro, FIPE, São Paulo, 2002.

DELGADO, M. G. Curso de Direito do Trabalho, 10 ed., São Paulo: LTr, 2011.

HIAVEGATTO, C . V. A Atenção Primária e sua percepção quanto ao desenvolvimento de ações de Saúde do Trabalhador no SUS em Minas Gerais. 2010. 128 f. Dissertação (Mestrado em Saúde Pública)-Universidade Federal de Minas Gerais, Belo Horizonte, MG, 
2010. Disponível em http://www.scielo.br/scielo.php?script=sci_arttext\&pid=S030376572013000100005 . Acesso em 08 ago 2016.

MARTINS, S. P. Direito do trabalho. 29. ed., rev. atual. e ampl. São Paulo: Atlas, 2013.

MARX, K. O capital: critica da economia politica. Livro I. Tradução de Reginaldo Sant’Anna. 22 ed. Rio de Janeiro: Civiliazação Brasileira, 2004.

MEDEIROS NETO, X. T. Dano moral coletivo. 2. ed. São Paulo: LTr, 2007.

NUNES JUNIOR, V. S. A cidadania social na Constituição de 1988: estratégias de positivação e exigibilidade social na Constituição de 1988. São Paulo: Editora verbatim, 2009.

NUNES JUNIOR, V. S.; DALLARI, S. G. Direito Sanitario. São Paulo: Editora Verbatim, 2010 .

OLIVEIRA, Sebastião Geraldo de. Proteção jurídica à saúde do trabalhador. 2. ed. São Paulo: LTR, 1998.

SARLET, I. W. Dignidade da pessoa humana e direitos fundamentais na Constituição Federal de 1988, 2 ed., Porto Alegre: Livraria do Advogado, 2002.

SERRANO, M. A. M. O sistema único de saúde e suas diretrizes constitucuonais. 2 ed. São Paulo: Editora verbatim, 2012.

SILVA, A. R. O. A saúde do trabalhador como um direito humano. Revista do Tribunal Regional do Trabalho da 15 $^{\text {a }}$ Região, n. 31, 2007.

SILVA, J. A. R. O. A Flexibilização da Jornada de Trabalho e seus reflexo na saúde do trabalhador, Revista LTr, p. 181/192, v. 77, n 02, fev/2013. 
Limitação do tempo de trabalho e proteção à saúde dos trabalhadores - uma analise dos sistemas jurídicos brasileiro e espanhol. Revista LTr, p. 1189/1208, v. 76, out/2012.

TEIXEIRA, S.F. Reforma Sanitária: em busca de uma teoria. São Paulo: Cortez, 1989.

VASCONCELLOS, L.C.F. A municipalização como estratégia de consolidação da saúde do trabalhador no setor saúde. Rio de Janeiro: FOC, 1994. (Dissertação de Mestrado) Fundação Oswaldo Cruz, Escola nacional de Saúde Pública, 1994. 